\title{
Effects of Hippotherapy on Recovery of Gait and Balance Ability in Patients with Stroke
}

\author{
Chae-Woo Lee, PT, MS ${ }^{1)}$, Seong Gil Kim, PT, MS²), Min Sik Yong, PT, MS²** \\ 1) Department of Hippotherapy, Sungduk College, Republic of Korea \\ 2) Department of Rehabilitation Science, Graduate School, Daegu University: 15 Jillyang, \\ Gyeongsan-si, Gyeongbuk 712-714, Republic of Korea
}

\begin{abstract}
Purpose] The aim of this study was to examine the the effects of hippotherapy on gait and balance ability in patients with stroke. [Subjects and Methods] Thirty stroke patients were randomly divided into a hippotherapy group and a treadmill group and they conducted exercise for eight weeks. [Results] Berg Balance Scale score, gait velocity, and step length asymmetry ratio were significantly improved in the group receiving hippotherapy training. However, in the group receiving treadmill training, only step length asymmetry ratio was significantly improved. In the comparison between the hippotherapy group and treadmill group, there was no significant difference in Berg Balance Scale score, but a significant difference was found in gait velocity and step length asymmetry ratio. [Conclusion] The results of this study indicated that hippotherapy is a helpful treatment for stroke patients. Key words: Stroke, Balance, Hippotherapy
\end{abstract}

(This article was submitted Aug. 13, 2013, and was accepted Sep. 22, 2013)

\section{INTRODUCTION}

Stroke, one of the leading causes of death, results in neurological deficits such as hemiparesis. Hemiparetic patients generally show balance impairments, and the impairments lead to other problems: increased risk of fall, decreased activities of daily living (ADL), and limited mobility ${ }^{1-3)}$. Patients with stroke are also characterized by a disability with respect to independent walking, and all of these problems limit patients' quality of life ${ }^{4,5}$.

Physical therapy can be an effective method for solving these problems ${ }^{6}$. Hippotherapy, also known as horseback riding therapy, is a form of physical therapy strategy that uses equine movement ${ }^{7,8)}$. The concept of hippotherapy is to use a horse as a therapeutic tool, and it is based on similarities in gait between the human and horse ${ }^{9}$. The horse's gait provides patients having motor disabilities with rhythmic and repetitive movements similar to human walking, thereby giving them training opportunities to improve posture, balance, and strength.

Most research concerning hippotherapy has been confined to children with cerebral palsy up to now ${ }^{10)}$. Thus, it has been suggested that more studies related to hippotherapy on adult patients with other disorders such as brain injury need to be carried out. Because hippotherapy is able to have positive influences on balance or gait ability, it may be

*Corresponding author. Min Sik Yong (E-mail: peast4ever@ naver.com)

(C2014 The Society of Physical Therapy Science. Published by IPEC Inc. This is an open-access article distributed under the terms of the Creative Commons Attribution Non-Commercial No Derivatives (by-ncnd) License $<$ http://creativecommons.org/licenses/by-nc-nd/3.0/>. helpful in improving the motor abilities of stroke patients. For these reasons, the present study investigated about effects of hippotherapy on gait and balance ability in patients with stroke.

\section{SUBJECTS AND METHODS}

The present study was conducted with 30 stroke patients receiving exercise therapy at $\mathrm{H}$ horse riding place, $\mathrm{K}$ hospital and T hospital located in Gyeonggi-do. Subject characteristics are described in Table 1. Potential participants were included if they had a diagnosed stroke, ability to walk independently or more than 10 meters with walking aid, cognitive impairment defined as a Korean mini-mental state examination (MMSE-K) score of more than 24, spasticity in a paretic lower extremity defined as a Modified Ashworth Scale (MAS) grade of less than 2, no orthopedic problem able to obstruct performance of training programs, and ability to perform training for more than 30 minutes. All included participants provide written informed consent in accordance with the ethical standards of the Declaration of Helsinki.

All subjects were divided into 2 groups: a hippotherapy group $(n=15)$ and a treadmill group $(n=15)$. Each training intervention was conducted in 30-minutes sessions administered 3 days per week for 8 weeks. During each hippotherapy session, the horse walked around a circle with a diameter of 30 meters 30 times clockwise and 30 times counterclockwise over the course of 30 minutes. Treadmill training began with the minimum speed $0.1 \mathrm{~km} /$ hour, and then subjects maintained their individual maximum speed for 30 minutes.

In the present study, the Berg Balance Scale (BBS) was 
Table 1. General characteristics of subjects

\begin{tabular}{lll}
\hline & Hippotherapy & Treadmill \\
\hline Gender $(\mathrm{M} / \mathrm{F})$ & $11 / 4$ & $12 / 3$ \\
Age $($ year) & $63.8 \pm 6.2$ & $64.3 \pm 4.8$ \\
Height $(\mathrm{cm})$ & $160.3 \pm 4.5$ & $160.3 \pm 3.6$ \\
Weight $(\mathrm{kg})$ & $57.5 \pm 5.1$ & $57.5 \pm 4.8$ \\
\hline
\end{tabular}

Mean \pm SD

measured for an assessment of balance ability, and gait velocity and step length asymmetry ratio (\%) were also measured by AP1105 to assess gait ability. All measured values were reported as the mean \pm standard deviation. SPSS for Windows (version 18.0) was used to analyze the data of the present study. The paired t-test was used to examine differences between before and after intervention, and the independent t-test was used to examine differences between the groups. The statistical significance level was set to $\alpha=0.05$.

\section{RESULTS}

BBS score, gait velocity, and step length asymmetry ratio were significantly improved in the group receiving hippotherapy training $(\mathrm{p}<0.05)$. However, in the group receiving treadmill training, only the step length asymmetry ratio was significantly improved $(\mathrm{p}<0.05)$. In the comparison between the hippotherapy group and treadmill group, there was no significant difference in BBS score, but a significant difference was found in gait velocity and step length asymmetry ratio $(\mathrm{p}<0.05)($ Table 2$)$.

\section{DISCUSSION}

There has been an increase in the incidence of stroke because the average life expectancy is growing longer. Among various stroke sequelae, the high risk of falling is considered as a remarkable concern for the health of hemiparetic patients ${ }^{11)}$. Stroke patients with balance impairments have limitations in their gait ability, and the limited gait performance might lead to an increase in fall risk $^{3}$. The problems with respect to gait ability result in reduced gait speed, which is related to step length asymmetry ${ }^{12}$. Step length asymmetry, a phenomenon resulting from hemiparesis, which is defined as a difference in step length between the paretic and non-paretic lower extremity $\left.{ }^{13}, 14\right)$. The changes in gait speed and step length might provide stroke patients with stability, but they are compensatory movements resulting from increased fall risk $^{15}$. In order to return a compensatory gait to a normal gait, studies with regard to treatment methods able to improve gait and balance ability of stroke patients should be conducted.

In the present study, the step length asymmetry ratio was significantly decreased in both the treadmill group and the hippotherapy group after each training intervention. In addition, the hippotherapy training group showed a significant increase in gait speed as well as BBS score. These results demonstrated that hippotherapy not only increases gait velocity and step length, but also improves balance ability. Espy et al. suggested that there is a direct
Table 2. Comparison of measurement values before and after the intervention

\begin{tabular}{llll}
\hline Variable & Group & Before & After \\
\hline Berg Balance & Hippotherapy & $40.4 \pm 1.5$ & $42.7 \pm 3.2^{\mathrm{a}}$ \\
Scale (score) & Treadmill & $40.5 \pm 1.5$ & $41.7 \pm 5.1$ \\
Gait velocity & Hippotherapy & $38.3 \pm 0.4$ & $39.6 \pm 0.8^{\mathrm{ab}}$ \\
(cm/sec) & Treadmill & $38.4 \pm 0.4$ & $38.8 \pm 0.8^{\mathrm{b}}$ \\
Step length asym- & Hippotherapy & $0.32 \pm 0.05$ & $0.19 \pm 0.05^{\mathrm{ab}}$ \\
metry ratio (\%) & Treadmill & $0.32 \pm 0.04$ & $0.29 \pm 0.06^{\mathrm{ab}}$ \\
\hline
\end{tabular}

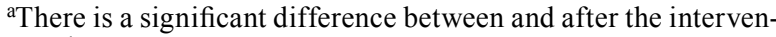
tion, ${ }^{b}$ There is a significant difference between the hippotherapy and treadmill groups after the intervention.

relationship between decreased gait velocity and increased risk of falling ${ }^{15}$. Judging from this statement, hippotherapy might have positive influences on the reduction of fall risk through increasing gait velocity and step length. Furthermore, Hsiao-Wecksler and Robinovitch reported that balance recovery is much more difficult to achieve in elderly people compared with young people because gait velocity and step length are reduced in elderly people ${ }^{16)}$. From the results of the present study, it is suggested that hippotherapy might improve balance ability of stroke patients through enhancement of both gait velocity and step length.

Although the step length asymmetry ratio was significantly decreased in the treadmill group after training, the result value attained by applying treadmill training was higher than that attained by hippotherapy training. The present study showed that both balance ability and gait velocity increased in the treadmill group, but the differences were not significant. In the comparison of the treadmill group and the hippotherapy group, there was no significant difference in BBS score. A significant difference between the two experimental groups was found in gait velocity as well as step length asymmetry ratio. From all results, it is suggested that hippotherapy training might have more powerful effects on improvements of balance ability, gait velocity, and step length asymmetry ratio than treadmill training. Hippotherapy provides patients with thousands of repetitive stimulations for postural challenge. The movements of the horse make patients experience new information from the vestibular and proprioceptive senses, and patients might achieve recovery of postural balance through adaptation to this information $\left.{ }^{7}, 8\right)$. Because of all of these advantages and the similarity to human gait, the present study suggests that hippotherapy might have more considerable effects on gait and balance performance than treadmill training.

In conclusion, hippotherapy is a helpful treatment method for stroke patients. There are several limitations in the present study. Both the treadmill training and hippotherapy training were conducted for only 8 weeks, so further study is necessary to examine how long effects of hippotherapy can last. Also, additional assessment tools for gait or balance should be included to demonstrate obvious results. In terms of these limitations, the present study suggests that further study should be carried out to provide stroke patients with efficient hippotherapy. 


\section{REFERENCES}

1) Ivey FM, Hafer-Macko CE, Macko RF: Task-oriented treadmill exercise training in chronic hemiparetic stroke. J Rehabil Res Dev, 2008, 45: 249. [Medline] [CrossRef]

2) Tyson SF, Hanley M, Chillala J, et al.: Balance disability after stroke. Phys Ther, 2006, 86: 30-38. [Medline]

3) de Oliveira CB, De Medeiros I, Frota N, et al.: Balance control in hemiparetic stroke patients: main tools for evaluation. J Rehabil Res Dev, 2008 45: 1215-1226. [Medline] [CrossRef]

4) Salzman B: Gait and balance disorders in older adults. Am Fam Physician, 2010, 82: 61-68. [Medline]

5) Lau KW, Mak MK: Speed-dependent treadmill training is effective to improve gait and balance performance in patients with sub-acute stroke. J Rehabil Med, 2011, 43: 709-713. [Medline] [CrossRef]

6) Jette DU, Latham NK, Smout RJ, et al.: Physical therapy interventions for patients with stroke in inpatient rehabilitation facilities. Phys Ther, 2005, 85: 238-248. [Medline]

7) Han JY, Kim JM, Kim SK, et al.: Therapeutic effects of mechanical horseback riding on gait and balance ability in stroke patients. Ann Rehabil Med, 2012, 36: 762-769. [Medline] [CrossRef]

8) Beinotti F, Correia N, Christofoletti G, et al.: Use of hippotherapy in gai training for hemiparetic post-stroke. Arq Neuropsiquiatr, 2010, 68: 908 913. [Medline] [CrossRef]

9) Herrero P, Asensio Á, García E, et al.: Study of the therapeutic effects of an advanced hippotherapy simulator in children with cerebral palsy: a randomised controlled trial. BMC Musculoskelet Disord, 2010, 11: 71 [Medline] [CrossRef]

10) Sunwoo H, Chang WH, Kwon J-Y, et al.: Hippotherapy in adult patients with chronic brain disorders: a pilot study. Ann Rehabil Med, 2012, 36: 756-761.[Medline] [CrossRef]

11) Weerdesteyn V, de Niet M, van Duijnhoven HJ, et al.: Falls in individuals with stroke. J Rehabil Res Dev, 2008, 45: 1195-1213. [Medline] [CrossRef]

12) Balasubramanian CK, Bowden MG, Neptune RR, et al.: Relationship between step length asymmetry and walking performance in subjects with chronic hemiparesis. Arch Phys Med Rehabil, 2007, 88: 43-49. [Medline] [CrossRef]

13) Roerdink M, Beek PJ: Understanding inconsistent step-length asymmetries across hemiplegic stroke patients impairments and compensatory gait. Neurorehabil Neural Repair, 2011, 25: 253-258. [Medline] [CrossRef]

14) Capó-Lugo CE, Mullens $\mathrm{CH}$, Brown DA: Maximum walking speeds obtained using treadmill and overground robot system in persons with poststroke hemiplegia. J Neuroeng Rehabil, 2012, 9: 80. [Medline] [CrossRef]

15) Espy DD, Yang F, Bhatt T, et al.: Independent influence of gait speed and step length on stability and fall risk. Gait Posture, 2010, 32: 378-382. [Medline] [CrossRef]

16) Hsiao-Wecksler ET, Robinovitch SN: The effect of step length on young and elderly women's ability to recover balance. Clin Biomech (Bristol, Avon), 2007, 22: 574-580. [Medline] [CrossRef] 